\title{
ORIGINAL ARTICLE PSYCHOMETRIC PROPERTIES OF THE TURKISH VERSION OF THE CARDIAC HEALTH BEHAVIOR SCALE
}

\author{
Emine Kaplan Serin ${ }^{1}$, Seyhan Çıtlık Sarıtaș ${ }^{2}$ \\ ${ }^{1}$ Gaziantep University, Gaziantep, Turkey, ${ }^{2}$ İnönü University, Malatya, Turkey
}

\begin{abstract}
Objectives: This methodological study was carried out to test the validity and reliability of the Cardiac Health Behavior Scale (CHBS-21) for its use in Turkey among coronary artery patients. Methodology: The population included individuals visiting the cardiology polyclinic of a university hospital and being followed up with the diagnosis of coronary artery disease, while the sample consisted of 229 volunteering patients who satisfied the inclusion criteria. The data were gathered by using a Patient Information Form that includes the descriptive characteristics of the participants and the Turkish form of the Cardiac Health Behavior Scale. SPSS (24.0) and AMOS were used in data analysis which included exploratory and confirmatory factor analyses. Results: The Cronbach's alpha value of the scale was 0.92 . The values for the dimensions of the scale were as 0.77 for health responsibility, 0.60 for physical activity, 0.76 for dietary habits, 0.71 for stress management and 0.85 for quitting smoking. The goodness of fit index values in the Confirmatory Factor Analysis were found as: $\mathrm{X} 2=287.236, \mathrm{df}=176(\mathrm{p}<0.01)$, $\mathrm{X} 2 / \mathrm{df}=1.63, \mathrm{RMSEA}=0.053, \mathrm{GFI}=0.90, \mathrm{CFI}=0.94$ and $\mathrm{IFI}=0.94$. The model was found to show acceptable fit.

Conclusion: The Cardiac Health Behavior Scale is a valid and reliable instrument that may be used in the assessment of medical statuses and risk factors of individuals with coronary artery disease. The effective implementation of the patient education will be improved by this measurement instrument.
\end{abstract}

Keywords: Cardiac Health Behavior Scale; Coronary artery disease; Nursing; Reliability; Validity

Citation: Serin EK, Sarıtaş SÇ. Psychometric Properties of the Turkish Version of the Cardiac Health Behavior Scale. Pak Heart J. 2021;54(02):191-197. DOI: https://doi.org/10.47144/phj.v54i2.2098

\section{INTRODUCTION}

Cardiovascular diseases (CVD) have a significant role in the death in Turkey and worldwide. ${ }^{1-7}$ According to the data of the Turkish Statistical Institute (TURKSTAT), 39.8\% of the total deaths in 2016 were a result of CVD.5 Considering the severity of CVDs and their burden created on the country's economy, it is important for healthcare professionals to manage risks regarding the care for and prevention of the disease. ${ }^{8-11}$

Most cardiovascular diseases may be preventable, or their progression may be stopped by reducing changeable risk factors such as unhealthy diet, lack of physical activity, stress, body weight, smoking and alcohol consumption. ${ }^{8,9,12,13}$ WHO states that more than three-thirds of all CVD-related deaths may be prevented by healthy lifestyle behaviors, and quality of life may be increased..$^{8,14,15}$ Lifestyle changes reduce the recurrence of cardiovascular diseases and disease-related mortality rates. ${ }^{9}$ To reduce risk factors, individuals need to adopt healthy lifestyle behaviors. ${ }^{5}$

A healthy lifestyle has been defined as the individual managing all their behaviors that could affect their health and applying behaviors that are suitable for their health status in daily life. The
World Health Organization reported that $60 \%$ of the quality of health of individuals originates from their behaviors and lifestyles. ${ }^{5}$ To improve the health status and prevent the development or progression of the disease, individuals with CVD or risk of CVD need to sustain daily health behaviors such as quitting smoking, healthy nutrition, and regular exercise. ${ }^{89}$ For this, they need to have sufficient knowledge on risk factors. ${ }^{9}$

Providing individuals with healthy lifestyle behaviors and reducing their disease risk are among the main functions of healthcare professionals. ${ }^{10}$ Nurses take on roles in determining risky behavior, planning suitable interventions towards behavioral change and implementing these interventions. ${ }^{10}$ For this, there needs to exist a valid and reliable scale to assess the statuses of individuals with CVD or risk of CVD. ${ }^{8}$ Tools that are used to measure the health behaviors of individuals with CVD or risk of CVD should reflect the significant behaviors related to these risks in their daily lives. ${ }^{8}$ The 5 -dimensional Cardiac Health Behavior Scale (health responsibility, physical activity, dietary habits, stress management and quitting smoking) is a valid measurement tool. $^{8}$ A valid and reliable measurement instrument towards measuring the 
health behaviors of individuals with CVD could not be encountered in Turkey. Investigating healthy lifestyle behaviors in patients with diagnoses of CVD will contribute to shaping patient education programs, developing existing practices, improving cardiovascular health and reducing mortality rates and national health expenditures. ${ }^{5,9}$ The purpose of this study is to create the Turkish version of CHBS21 and examine its psychometric properties.

\section{METHODOLOGY}

The population of this descriptive cross sectional study consisted of patients monitored with the diagnosis of coronary artery disease and visited the cardiology polyclinic of a university hospital in Malatya in Turkey between December 2019 and January 2020. In methodological studies, the sample size is expected to be 5-10 times the number of items in the scale. ${ }^{16}$ In the study, for the 21 -item scale, a sample size of 10 times was determined, and it was planned to include at least 210 patients. The sample of the study included 229 randomly selected patients who volunteered to participate in the study, were being monitored with the diagnosis of coronary artery disease for at least 6 months, at or over the age of 18 years, could establish healthy communication, did not have any hearing and/or speech problem and were literate and provided informed consent.

Descriptive information form was prepared by the researchers in line with the literature and consisted of 10 questions on the sociodemographic and descriptive characteristics of the patients. The form questioned the sociodemographic (age, sex, education level, marital status, occupation and income level) and disease-related characteristics (BMI, presence of comorbidities, presence of heart disease in family and stress status) of the patients. Cardiac health behavior scale (CHBS) was developed for the first time in 2000 by Song and Lee to assess the cardiac-related health behaviors of individuals with coronary artery disease. ${ }^{17}$ The 25 item scale which was formed out of a 30-item pool was assessed under the titles of health responsibility, physical activity, dietary habits (nutritional habits and preferences), stress management and quitting smoking (content validity index > 0.80). ${ }^{18}$ CHBS has been used in various studies to measure the health behaviors of adults with CVD or risk of CVD. It is a 4-point Likert-type scale $(1=$ never, $2=$ sometimes, $3=$ usually and 4 $=$ routinely). In the quitting smoking part of the 25 item scale, 4 points are added for non-smokers in the calculation of the total score. The scale consists of 5 items for health responsibility, 4 items for physical activity, 8 items for dietary habits, 5 items for stress management and 3 items for quitting smoking. In the study conducted by Song et al., 4 items (items 12,17, 18 and 20) were not included in CHBS 21. The reliability coefficients of the scale were found as 0.83 for the total scale ( 21 items), 0.76 for health responsibility ( 6 items), 0.76 for physical activity (4 items), 0.70 for dietary habits ( 5 items: 0.68 for eating habits and 0.76 for food preference), 0.58 for stress management ( 3 items) and 0.70 for quitting smoking ( 3 items). ${ }^{8}$

At the stage of adapting CHBS into Turkish, the scale was translated from its original language of English into Turkish by four independent experts who were fluent in English and Turkish. After the experts completed the translations, the researchers examined the translations, selected the most suitable ones from the translated statements and gave the scale its final form. After this, the version of the scale that was translated into Turkish was sent to another expert who had not seen the original scale and was native-level fluent in English and Turkish, and the expert was asked to translate the scale from Turkish back to English. Afterwards, the author compared the back-translation of the scale and its original form, made the necessary adjustments and consulted another expert who was native-level fluent in English regarding the back-translated scale and asked the expert to compare the Turkish version and the original form in terms of meaning and similarity. The scale took its final form upon the recommendations received from the expert.

Content and Construct Validity

After language adaptation, for the latest form of the scale, the opinions of 10 experts working as faculty members in the fields of Internal Medicine Nursing and Cardiology were received. The experts were asked to assess the draft scale with scores of 1-4 in terms of suitability of language/expressions and content. The Davis technique was used for the content validity of the scale. ${ }^{19-22}$ In the Davis technique, experts report their views on items with a 4-point scoring system as "(1) suitable", "(2) highly suitable, requires moderate revision", "(3) slightly suitable, requires heavy revision" and "(4) unsuitable". While assessing each item, by dividing the number of the experts marking " 1 " or " 2 " by the number of all experts, the content validity index (CVI) for each item is obtained, and CVI values of higher than 0.8 indicate that the items are suitable in terms of content validity. ${ }^{24}$ No item was removed from the scale. CVI, which was recommended to be 0.80 or higher by Davis, was found to be in the range of $0.85-1.00$ for the items. As a result of the calculation made according to these values, the content validity index of the draft scale was determined as 0.97 . 
For the content validity of the scale, the opinions of 10 experts on the suitability of the items were collected, Kendall W was found as 0.292 with $\mathrm{p}<0.05$ in the assessment of the agreement among the opinions, and it was determined that the scale was applicable to the Turkish culture.

A cognitive assessment of this latest version of the scale was conducted on 15 individuals representing the target audience, and as a result of this, no negative feedback was received regarding the comprehensibility of the items. The data of the patients who were included in the preliminary application were not included in the analyses.

After linguistic validity and content validity were analyzed, the next step was the data collection stage. The data collection stage was carried out between 1 December 2019 and 30 January 2020 at the cardiology unit of a university hospital in Malatya in Turkey. The Descriptive Information Form and the Cardiac Health Behavior Scale were applied on 229 patients satisfying the inclusion criteria. As the scale is a self-reported scale, it was given to the patients, and the patients were asked to fill it. It took approximately 15 minutes to apply the data collection forms. To assess test-retest reliability, after 15 days following the first application, the scale was applied again on 30 individuals from the sample.

The statistical analysis of the data was carried out with the SPSS (version WIN 24.0) software. In examination on the sociodemographic data, descriptive statistics as percentages, frequencies, medians, minimum-maximum values, means and standard deviations were utilized. To determine the content validity of the scale, analyses were carried out on the content validity ratio (CVR) and content validity index values. ${ }^{19-23}$ For the purpose of assessing the agreement among expert opinions on the suitability of the items for the content validity of the scale, the Kendall W (Kendall Coefficient of Concordance) agreement test was applied on the expert opinions. The Kendall coefficient of concordance can vary between 0 and $1 .{ }^{19,20}$ For the construct validity of the scale, the EFA (exploratory factor analysis) and CFA (confirmatory factor analysis) techniques were used. The principal component analysis method was used in the EFA. Varimax rotation was applied, and the factor formation status of the scale was examined. To test the adequacy of the sample size, the Kaiser-MeyerOlkin (KMO) test statistic was calculated. Additionally, to determine the suitability of the scale items for analysis, Bartlett's test of sphericity was conducted. The KMO value needs to be higher than 0.5 , while the Bartlett's test of sphericity result needs to be $\mathrm{p}<0.05 .{ }^{19-24}$
The Cronbach's alpha internal consistency coefficient was calculated for the total scale and its dimensions to determine the reliability of the scale. In the Cronbach's alpha values, those above 0.7 were accepted as adequate. Additionally, when items were removed, the Cronbach's alpha values were also calculated and assessed. Item-total correlation values, which are generally desired to be higher than 0.3-0.4, were also calculated. Whether or not the scale had the property of additivity was tested (Tukey Non-additivity test).

The factor structure of the scale and its factor loads were examined by confirmatory factor analysis. Confirmatory factor analysis was conducted to assess the item-dimension structure of the scale. Among the summary fit index values, chisquared/degrees of freedom $(\chi 2 / \mathrm{df})$, Root Mean Square Error of Approximation (RMSEA), Comparative Fit Index (CFI), Standardized Root Mean Residual (SRMR) and Incremental Fit Index (IFI) values were given. For these values, several fit and cutoff points have been reported in the literature. Among the summary fit index values of the model, it is desired that the $\chi 2 / \mathrm{df}$ value is smaller than 3, the RMSEA and SRMR values are smaller than 0.08 , the CFI and IFI values are greater than 0.90 , and the GFI value is greater than 0.95 for an acceptable fit. ${ }^{19-24}$

The path diagram of the scale was created using the AMOS (version 20.0) program. Pearson's correlation test was utilized to determine the relationship between repeated measurements. ${ }^{22}$ In determining the consistency of the scale in time, the correlation that is obtained needs to be positive, high and greater than at least $0.70 .{ }^{20}$

For testing the Turkish validity and reliability of the scale, permission was received from Rhayun Song via electronic mail. For conducting the study, approval was received from the Non-Interventional Studies Ethics Board of a university (2018/ 2704), and permission was obtained from the chief physician's office of the hospital where the study was conducted. The principle of volunteerism was taken as a basis in participation. The individuals who agreed to participate in the study were informed about the study with a voluntary consent form in line with the Declaration of Helsinki, and their written consent was obtained.

\section{RESULTS}

The mean age of the participants was $52.92+12.48$, while their mean BMI was $27.06+3.52$. Among the participants, $43.2 \%$ were male, $81.7 \%$ were married, $47.6 \%$ were high school graduates, the income of $47.6 \%$ was equal to their expense, $23.3 \%$ were civil servants, $41.5 \%$ stated that they were 
stressed, 59.2\% had HT as a comorbidity, and $46.3 \%$ had heart disease in the family (Table 1 ).

Table 1: Distribution of the sociodemographic characteristics of the patients

\begin{tabular}{|l|c|c|}
\hline Characteristics & N & \% \\
\hline Sex & & \\
\hline Female & 99 & 43.2 \\
\hline Male & 130 & 43.2 \\
\hline Marital status & 187 & \\
\hline Married & 42 & 81.7 \\
\hline Single & & \\
\hline Education status & 36 & 18.3 \\
\hline Primary-secondary school & 109 & 47.6 \\
\hline High school & 84 & 36.7 \\
\hline Higher education & & \\
\hline Income level & 36 & 15.7 \\
\hline Income less than expense & 159 & 47.6 \\
\hline Income and expense equal & 34 & 36.7 \\
\hline Income more than expense & & \\
\hline Occupation & 78 & 34.1 \\
\hline Homemaker & 24 & 10.5 \\
\hline Laborer & 74 & 32.3 \\
\hline Civil servant & 53 & 23.1 \\
\hline Retired & & \\
\hline Stress status & 95 & 41.5 \\
\hline Yes & 134 & 58.5 \\
\hline No & & \\
\hline Comorbidity* & 40 & 29.6 \\
\hline DM & 80 & 59.2 \\
\hline HT & 15 & 10.2 \\
\hline Respiratory & & \\
\hline Heart disease patient in family & 106 & 46.3 \\
\hline Yes & $52.92+12.48(18-78)$ \\
\hline No & $27.06+3.52$ \\
\hline Age (years) & & \\
\hline BMI (kg/m ${ }^{\text {) }}$ & & \\
\hline * Asessment was made over 135 patient & & \\
\hline
\end{tabular}

*Assessment was made over 135 patient responses

The experts' opinions were assessed using the Davis technique, and the CVI value for all items was found as 0.97. For the Kendall W test, among the responses of the experts to the scale questions, there was no significant difference between the medians (Kendall W $=0.292, \mathrm{P}<0.05$ ). This result showed that the expert opinions had a consensus on the applicability of the scale items to a statistically significant extent. It was determined that the statements in the form were suitable for the Turkish culture, and they represented the field to be measured.

The distribution characteristics and reliability analysis of the scale and the mean scores and standard deviations of the five dimensions of CHBS 21 are shown in Table 2. The Cronbach's alpha values of the 5 -factor scale were as 0.77 for "health responsibility", 0.70 for "physical activity", 0.76 for "dietary habits", 0.71 for "stress management" and 0.85 for "quitting smoking". The Cronbach's alpha value of the total scale was 0.92 (Table 2). As a result of the "Tukey Non-Additivity" test that was conducted $(\mathrm{p}<0.001)$, it was found that the scale had additivity and was suitable for obtaining a total score. The mean total score of the scale was found as $56.22 \pm 10.12(37-84)$. The mean scores for the dimensions were as "health responsibility": 16.84+3.19 (9-24), "physical activity": 10.89+2.35 (5-16), "dietary habits": $13.20+2.71$ (7-20), "stress management": 7.90+1.82 (3-12) and "quitting smoking": $7.37+2.09$ (3-12). In the analysis, the item-total correlation values varied between 0.47 and 0.70 , and the scale had high internal consistency.

To measure time-invariance by the test-retest method, the scale was applied again on 30 of the patients after 15 days. The correlation coefficients obtained accordingly were 0.89-0.97 ( $\mathrm{p}<0.001$ ).

KMO and Bartlett's tests were conducted to see whether or not the data of the scale were suitable for factor analysis, and the results showed that the data were homogenous, and factor analysis could be conducted on the variables $(\mathrm{KMO}=0.920$, Bartlett's test of sphericity $=\mathrm{P}<0.001)$.

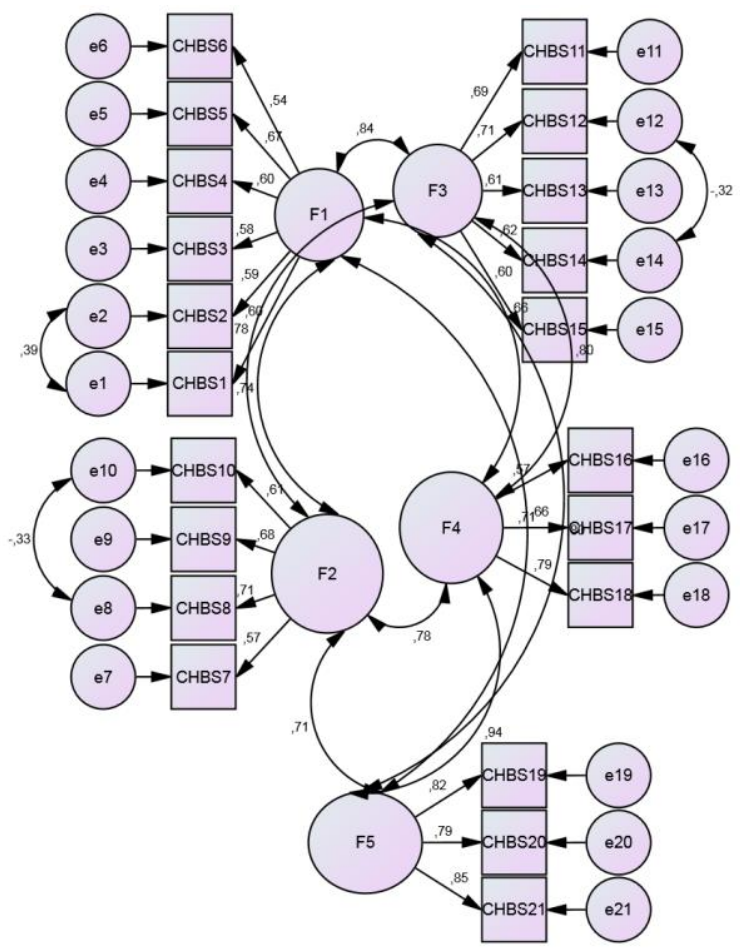

Figure 1: CFA Path Diagram of CHBS-21

The CFA path diagram of CHBS-21 is shown in Figure 1. Whether or not the exploratory factor analysis results and the five factors in the original scale were compatible was analyzed with the Varimax rotation method and eigenvalues, the items were limited based on the five factors for this purpose, and the grouping in the original scale was obtained. Factor 1 constituted the health 
responsibility dimension and contained 6 items (1, $2,3,4,5,6)$. This factor explained the variance in the scale by $60 \%$. Factor 2 constituted the physical activity dimension and contained 4 items (7, 8, 9, 10). This factor explained the variance in the scale by $61 \%$. Factor 3 constituted the dietary habits dimension and contained 5 items $(11,12,13,14$, 15). This factor explained the variance in the scale by $65 \%$. Factor 4 constituted the stress management dimension and contained 3 items $(16,17,18)$. This factor explained the variance in the scale by $60 \%$. Factor 5 constituted the quitting smoking dimension and contained 3 items $(19,20,21)$. This factor explained the variance in the scale by the highest amount of $70 \%$. The five-factor construct explained $61.8 \%$ of the variance. We observed that the factor loads of CHBS-21 were distributed between 0.47 and 0.76 . It was determined that the factor structure was valid (Table 2).
To assess whether or not the 21-item construct belonging to five dimensions of the scale was confirmed, a Confirmatory Factor Analysis (CFA) was applied. The CHBS CFA goodness of fit index values were found as $\mathrm{X} 2=344.236, \mathrm{df}=179$ $(\mathrm{p}<0.01), \mathrm{X} 2 / \mathrm{df}=1.92, \mathrm{RMSEA}=0.064, \mathrm{GFI}=0.88$, $\mathrm{CFI}=0.91$ and $\mathrm{IFI}=0.91$. In the assessment, a good fit could not be achieved in terms of the GFI value. At this stage of the analysis, modification recommendations were examined, and it was determined that the error covariances between the items 1-2, 8-9 and 12 and 14 were high. By relating the error covariances of the items in question, a second CFA model was applied. After the change that was made, the CFA goodness of fit indices were found as $\mathrm{X} 2=287.236, \mathrm{df}=176 \quad(\mathrm{p}<0.01)$, $\mathrm{X} 2 / \mathrm{df}=1.63, \mathrm{RMSEA}=0.053, \mathrm{GFI}=0.90, \mathrm{CFI}=0.94$ and IFI=0.94. The model was found to show an acceptable fit.

Table 2: Item-Total Score Correlation Coefficients, Factor Loadings, Alpha Coefficients and Explained Variance

\begin{tabular}{|c|c|c|c|c|c|c|c|c|}
\hline Scale items & $\begin{array}{l}\text { Health } \\
\text { respons } \\
\text { ibility }\end{array}$ & $\begin{array}{l}\text { Physica } \\
\text { l } \\
\text { activity }\end{array}$ & $\begin{array}{l}\text { Eating } \\
\text { behavio } \\
\mathbf{r}\end{array}$ & $\begin{array}{l}\text { Stress } \\
\text { manage } \\
\text { ment }\end{array}$ & $\begin{array}{l}\text { Smokin } \\
\text { g } \\
\text { cessatio } \\
\text { n }\end{array}$ & Mean (SD) & $\begin{array}{l}\text { Corrected Item- } \\
\text { total Correlations }\end{array}$ & $\begin{array}{l}\text { Cronbach's Alpha if } \\
\text { Item Deleted }\end{array}$ \\
\hline 1 & 0.74 & & & & & $2.9(0.7)$ & 0.53 & 0.91 \\
\hline 2 & 0.74 & & & & & $2.8(0.7)$ & 0.52 & 0.91 \\
\hline 3 & 0.62 & & & & & $2.8(0.7)$ & 0.47 & 0.91 \\
\hline 4 & 0.50 & & & & & $2.7(0.7)$ & 0.48 & 0.91 \\
\hline 5 & 0.47 & & & & & $2.7(0.7)$ & 0.57 & 0.91 \\
\hline 6 & 0.58 & & & & & $2.6(0.8)$ & 0.49 & 0.91 \\
\hline 7 & & 0.57 & & & & $2.7(0.8)$ & 0.51 & 0.91 \\
\hline 8 & & 0.59 & & & & $2.7(0.8)$ & 0.56 & 0.91 \\
\hline 9 & & 0.58 & & & & $2.7(0.8)$ & 0.57 & 0.91 \\
\hline 10 & & 0.71 & & & & $2.6(0.8)$ & 0.51 & 0.91 \\
\hline 11 & & & 0.67 & & & $2.6(0.7)$ & 0.62 & 0.91 \\
\hline 12 & & & 0.51 & & & $2.7(0.7)$ & 0.61 & 0.91 \\
\hline 13 & & & 0.71 & & & $2.6(0.7)$ & 0.53 & 0.91 \\
\hline 14 & & & 0.75 & & & $2.5(0.7)$ & 0.55 & 0.91 \\
\hline 15 & & & 0.64 & & & $2.5(0.7)$ & 0.57 & 0.91 \\
\hline 16 & & & & 0.63 & & $2.7(0.7)$ & 0.52 & 0.91 \\
\hline 17 & & & & 0.65 & & $2.6(0.7)$ & 0.58 & 0.91 \\
\hline 18 & & & & 0.60 & & $2.5(0.7)$ & 0.66 & 0.91 \\
\hline 19 & & & & & 0.69 & $2.5(0.7)$ & 0.69 & 0.91 \\
\hline 20 & & & & & 0.76 & $2.4(0.7)$ & 0.66 & 0.91 \\
\hline 21 & & & & & 0.76 & $2.4(0.7)$ & 0.70 & 0.91 \\
\hline $\begin{array}{l}\text { \% Variance } \\
\text { Explained }\end{array}$ & 0.60 & 0.61 & 0.65 & 0.60 & 0.70 & & & Total $=61.8$ \\
\hline $\begin{array}{c}\text { Cronbach } \\
\text { alpha }\end{array}$ & 0.77 & 0.70 & 0.76 & 0.71 & 0.85 & & & Total $=0.92$ \\
\hline
\end{tabular}

\section{DISCUSSION}

The Content Validity Ratio and Content Validity Index values of the Cardiac Health Behavior Scale were examined. As the number of the experts in our study was 10, it was found that the items with a CVR value of 0.85 provided content validity. The CVI value was found as 0.97. These values demonstrated that the Cardiac Health behavior Scale satisfied content validity. The opinions of 10 experts were collected on the suitability of the items for the content validity of the scale, the analysis results revealed that Kendall $\mathrm{W}=0.292, \mathrm{p}<0.05$, and it was determined that the scale was applicable to the Turkish culture.

To determine whether or not the scale data were suitable for factor analysis, KMO and Bartlett's tests were conducted, and the obtained results showed that the data 
were homogenous, and factor analysis could be conducted on the variables. The Bartlett's test of sphericity result was $\chi 2=2068.458(\mathrm{df}=210, \mathrm{p}<0.001)$, and the Kaiser-Meyer-Olkin index was 0.92. In the original scale, the data were normally distributed, and EFA was applied. The Bartletts test of sphericity result was reported as $\chi 2=1246.20(\mathrm{df}=300, \mathrm{p}<0.001)$, and the Kaiser-Meyer-Olkin index was determined as $0.73{ }^{8}$ In our study, first of all, an Exploratory Factor Analysis (EFA) was conducted. In the results, we observed that the five-factor construct explained $61.8 \%$ of the variance, and the factor loads of CHBS-21 varied between 0.47 and 0.76 . These factor loads were higher than 0.30 , and the five-factor construct was valid. In the original scale, the cumulative factor load was found as 61.45 , and all factors exceeded $40 \% .^{8}$

Whether or not the factor structure of the Cardiac Health Behavior Scale was confirmed was examined with a firstlevel CFA. The CFA goodness of fit index values were found as $\mathrm{X} 2=287.236, \mathrm{df}=176(\mathrm{p}<0.01), \mathrm{X} 2 / \mathrm{df}=1.63$, RMSEA $=0.053, \mathrm{GFI}=0.90, \mathrm{CFI}=0.94$ and $\mathrm{IFI}=0.94$. The model was found to show an acceptable fit. In the original scale, the CFA goodness of fit index values were reported as $\mathrm{X} 2=243.18, \quad \mathrm{df}=175 \quad(\mathrm{p}<0.01), \quad \mathrm{X} 2 / \mathrm{df}=1.39$, RMSEA $=0.05, \mathrm{GFI}=0.87, \mathrm{CFI}=0.92$ and $\mathrm{IFI}=0.92 .^{8}$

To assess the reliability of the Cardiac Health Behavior Scale, the Cronbach's alpha value was calculated. The intervals in assessing the Cronbach's alpha coefficient were reported as $0.00<\alpha<0.40$ : not reliable, $0.40<\alpha<$ 0.60 : reliable on a low level, $0.60<\alpha<0.80$ : reliable and $0.80<\alpha<1.00$ : highly reliable. ${ }^{16,19-24}$ In our study, the Cronbach's alpha value of the Cardiac Health Behavior Scale was found as 0.92 , and this value showed that the scale had very high reliability. The Cronbach's alpha values of the dimensions of the scale were found as 0.77 for health responsibility, 0.70 for physical activity, 0.76 for dietary habits, 0.71 for stress management and 0.85 for quitting smoking. Regarding the Cronbach's alpha values of the dimensions of the scale, it was concluded that the reliability of the measurement instrument was sufficient. Likewise, the Cronbach's alpha value for the Cardiac Health Behavior Scale developed by Song et al. (2018) was reported as 0.83 . They reported the dimensions' Cronbach's alpha values as 0.76 for health responsibility, 0.76 for physical activity, 0.70 for dietary habits, 0.58 for stress management and 0.70 for quitting smoking. ${ }^{8}$ Regarding the Cronbach's alpha values of the dimensions of the scale, it was concluded that the reliability of the measurement instrument was sufficient. As a result, the Cronbach's alpha values of the Cardiac Health Behavior Scale showed that its Turkish adaptation had high reliability. In this case, the high Cronbach's alpha values shown by the Turkish form indicate that the characteristics aimed to be measured with the original form are can also be consistently measured for the Turkish society, and the adaptation of the scale items to the Turkish society showed a consistency with the original form.

Another method that was applied to assess the reliability of the Cardiac Health Behavior Scale was test-retest reliability. In test-retest reliability, the researcher checks the correlation between scores obtained by applying a measurement instrument two times on the same group. To determine that a scale is time-invariant (shows stability), it is desired that the calculated correlation coefficient is positive and high, and this limit was reported as at least 0.70 for scales. $^{25}$ A reliability coefficient of 0.70 and higher is sufficient for a scale. In our study, according to the test-retest analysis, the correlation coefficient of the scale was 0.97 , which showed a sufficient agreement between the results. In this case, it was concluded that test-retest reliability was achieved. As the original scale was not tested for testretest reliability, the statistics could not be compared.

The fact that the study was conducted with only individuals with coronary artery disease was a limitation of the study. Additionally, this study was conducted at a single center, and it is limited to the patients who visited the cardiology polyclinic of the hospital where it was conducted. The study included patients who were being monitored with the diagnosis of coronary artery disease, were at or over the age of 18 , could establish healthy communication, did not have hearing and/or speech problems, were literate and volunteered to participate in the study.

\section{CONCLUSION}

As a result of this study, it was determined that the Cardiac Health Behavior Scale was a valid and reliable tool that could be used in the Turkish society. Additionally, it is recommended for the Cardiac Health Behavior Scale to be used as cardiology polyclinics and clinics and cardiac rehabilitation units to define the health statuses and risky behaviors of patients and conduct education programs based on the needs of patients.

\section{AUTHORS' CONTRIBUTION}

EKS: Concept and design, data acquisition, interpretation, drafting, final approval, and agree to be accountable for all aspects of the work. SÇS: Data acquisition, interpretation, drafting, final approval and agree to be accountable for all aspects of the work.

Conflict of interest: Authors declared no conflict of interest.

\section{REFERENCES}


1. Townsend N, Wilson L, Bhatnagar P, Wickramasinghe K, Rayner M, Nichols M. Cardiovascular disease in Europe: epidemiological update 2016. Eur Heart J. 2016;37(42):3232-45.

2. Rajati F, Rajati M. Validity and reliability of the Iranian version of the Cardiac Exercise Self-Efficacy Scale. ARYA Atheroscler. 2019;15(3):113-22.

3. Arikan İ, Metintas S, Kalyoncu C, Yıldız Z. The Cardiovascular Disease Risk Factors Knowledge Level (CARRF-KL) Scale: a validity and reliability study. Arch Turk Soc Cardiol. 2009;37(1):35-40.

4. Özkan Y, Taştan S. The validity and reliability study of the Turkish version of the Cardiac Symptom Survey. Turk Gogus Kalp Damar Cerrahisi Derg. 2016;24(3):480-8.

5. Persil Özkan Ö, Büyükünal ZK, YiğitZ, Inci Y, Sakar FS, Özçelik Ersü D. Evaluation of healty lifestyle behaviours of patients with cardiovascular heart disease. MEU J Health Sci. 2019;12(1):22-31

6. Chen S, Zheng S, Wang X, Zhang X, Fa T, Fu L, Et al. Linguistic and Psychometric Validation of the Chinese Version of the Control Attitudes Scale-Revised in Patients With Chronic Heart Failure. J Cardiovasc Nurs. 2020 May 2. DOI: 10.1097/JCN.0000000000000705 [Online ahead of print]

7. Koirala B, Budhathoki C, Dennison-Himmelfarb CR, Bhattarai P, Davidson PM. The Self-Care of Heart Failure Index: A psychometric study. J Clin Nurs. 2020;29(3-4):645-52.

8. Song R, Oh H, Ahn S, Moorhead S. Validation of the Cardiac Health Behavior Scale for Korean Adults with Cardiovascular Risks or Diseases. Appl Nurs Res. 2018;39:252-8.

9. Çürük GN, Korkut Bayındır S, Oğuzhan A. The relatıonshıp of the healthy lifestyle behaviors and cardiovascular disease risk factors knowledge level of patients with cardiovascular disease and their relatıves. E.U. Saglik Bilim Derg. 2018;27(1):40-7.

10. Gümüş Y, Kitiş Y. The Validity and Reliability of Exercise Behavior Change Scales. HUHEMFAD-JOHUFON. (2015);1-19

11. Taşkin Yilmaz F, Karakoç Kumsar A, Çelik S. The association between healthy lifestyle behaviors and knowledge levels about cardiovascular disease risk factors in people with type 2 diabetes. HEAD. 2018;15(2):63-70.

12. Li Y, Schoufour J, Wang DD, Dhana K, Pan A, Liu X, et al. Healthy lifestyle and life expectancy free of cancer, cardiovascular disease, and type 2 diabetes: prospective cohort study. BMJ. 2020;368:16669.

13. Lv J, Yu C, Guo Y, Bian Z, Yang L, Chen Y, et al. Adherence to Healthy Lifestyle and Cardiovascular Diseases in the Chinese Population. J Am Coll Cardiol. 2017;69(9):1116-25.
14. ESC Guides. European Guidelines on cardiovascular disease prevention in clinical practice (version 2012). Arch Turk Soc Cardiol. 2012;40(3):126-8.

15. Cosentino F, Grant PJ, Aboyans V, Bailey CJ, Ceriello A, Delgado V, et al. 2019 ESC Guidelines on diabetes, pre-diabetes, and cardiovascular diseases developed in collaboration with the EASD: The Task Force for diabetes, pre-diabetes, and cardiovascular diseases of the European Society of Cardiology (ESC) and the European Association for the Study of Diabetes (EASD). Eur Heart J. 2020;41(2):255-323.

16. İzgü N. Turkish adaptation of chemotherapy induced Alopecia Distress Scale: A validity and reliability study. Turkiye Klinikleri J Nurs Sci. 2020;12(2):227-35.

17. Song R., Lee H. Effects of the inpatient cardiac rehabilitation program on behavioral modification and quality of life in patients with coronary artery disease. J Korean Acad Nurs. 2000;30(2):463-75

18. Song R, June KJ, Ro YJ, Kim CG. Effects of motivationenhancing program on health behaviors, cardiovascular risk factors, and functional status for institutionalized elderly women. J Korean Acad Nurs. 2001;31(5):858-70.

19. Özel F, Özkraman A, Şenuzun Aykar F. The Valıdıty and Reliability Study: The Symptom Management Scale for SelfEfficacy. ACU Sağlık Bil Derg. 2019;10(1):67-72.

20. Konal Korkmaz E, Ardahan M. Psychometric Properties of the Turkish Version of the Dietary Sodium Restriction Questionnaire. J Cardiovasc Nurs. 2021;36:366-73.

21. Saritas SC, Cevik S, Ozden G, Salik S. Turkish Version of the Dutch Heart Failure Knowledge Scale: Validity and reliability. Pak Heart J. 2020;53(03):269-74.

22. Gök Metin Z, Helvaci A. Validity and Reliability of Turkish Version of the Dyspnea-12 Scale. HUHEMFAD-JOHUFON. 2018;5(2):102-15

23. Ağralı H, Akyar I. Turkısh valıdatıon and reliability of health lıteracy scale for diabetıc patıents. ACU Sağlık Bil Derg. 2018;9(3):314-21

24. Çetinkaya A, Elbi H, Altan S, Rahman S, Aydemir Ö. Adaptation of the Dementia Attitudes Scale into Turkish. Arch Neuropsychiatry.2020;57:325-32.

25. Buyukozturk S. Manual of Data Analysis for Social Sciences. Ankara, Turkey: Pegem Academy; 2011.

\section{Address for Correspondence:}

Dr. Emine Kaplan Serin, Gaziantep University, Gaziantep, Turkey.

Email: emine_3354@hotmail.com 